\title{
Two cases of mild serotonin toxicity via 5-hydroxytryptamine IA receptor stimulation
}

This article was published in the following Dove Press journal:

Neuropsychiatric Disease and Treatment

II February 2014

Number of times this article has been viewed

\author{
Hiroto Nakayama',* \\ Sumiyo Umeda ${ }^{2, *}$ \\ Masashi Nibuya ${ }^{3}$ \\ Takeshi Terao ${ }^{4}$ \\ Koichi Nisijima ${ }^{5}$ \\ Soichiro Nomura ${ }^{3}$ \\ 'Yamaguchi Prefecture Mental \\ Health Medical Center, Yamaguchi, \\ Japan; 'Department of Psychiatry, \\ NTT West Osaka Hospital, Osaka, \\ Japan; ${ }^{3}$ Department of Psychiatry, \\ National Defense Medical College, \\ Saitama, Japan; ${ }^{4}$ Department of \\ Neuropsychiatry, Oita University \\ Faculty of Medicine, Oita, Japan; \\ ${ }^{5}$ Department of Psychiatry, Jichi \\ University School of Medicine, \\ Tochigi, Japan \\ *These authors contributed equally \\ to this work
}

\begin{abstract}
We propose the possibility of 5-hydroxytryptamine (5-HT)1A receptor involvement in mild serotonin toxicity. A 64-year-old woman who experienced hallucinations was treated with perospirone $(8 \mathrm{mg} /$ day). She also complained of depressed mood and was prescribed paroxetine $(10 \mathrm{mg} /$ day $)$. She exhibited finger tremors, sweating, coarse shivering, hyperactive knee jerks, vomiting, diarrhea, tachycardia, and psychomotor agitation. After the discontinuation of paroxetine and perospirone, the symptoms disappeared. Another 81-year-old woman, who experienced delusions, was treated with perospirone ( $8 \mathrm{mg} /$ day). Depressive symptoms appeared and paroxetine $(10 \mathrm{mg} /$ day) was added. She exhibited tachycardia, finger tremors, anxiety, agitation, and hyperactive knee jerks. The symptoms disappeared after the cessation of paroxetine and perospirone. Recently, the effectiveness of coadministrating 5-HT1A agonistic psychotropics with selective serotonin reuptake inhibitors (SSRIs) has been reported, and SSRIs with 5-HT1A agonistic activity have been newly approved in the treatment of depression. Perospirone is a serotonin-dopamine antagonist and agonistic on the 5-HT1A receptors. Animal studies have indicated that mild serotonin excess induces low body temperature through 5-HT1A, whereas severe serotonin excess induces high body temperature through 5-HT2A activation. Therefore, it could be hypothesized that mild serotonin excess induces side effects through 5-HT1A, and severe serotonin excess induces lethal side effects with hyperthermia through 5-HT2A. Serotonin toxicity via a low dose of paroxetine that is coadministered with perospirone, which acts agonistically on the 5-HT1A receptor and antagonistically on the 5-HT2A receptor, clearly indicated 5-HT1A receptor involvement in mild serotonin toxicity. Careful measures should be adopted to avoid serotonin toxicity following the combined use of SSRIs and 5-HT1A agonists.
\end{abstract}

Keywords: serotonin toxicity, 5-HT1A, 5-HT2A, paroxetine, perospirone

\section{Introduction}

Serotonin toxicity (or serotonin syndrome) is the result of excessive serotonin activity caused by the administration of selective serotonin reuptake inhibitors (SSRIs), often in combination with serotonin receptor agonists. ${ }^{1}$ Serotonin toxicity is characterized by myoclonus, hyperreflexia, autonomic nervous symptoms, and changes in mental status. ${ }^{1}$ Given that an altered mental status, which includes agitation and anxiety, is common in depression, patients treated with SSRIs should be carefully examined for the presence of hyperreflexia. Two serotonin receptor subtypes are candidates for the underlying pathophysiology of serotonin toxicity. ${ }^{1}$ However, the different effects of the stimulation of the 5-hydroxytryptamine (5-HT)1A and 5-HT2A receptors on the clinical exacerbation of serotonin toxicity have not yet been elucidated. In the present report, we suggest the possible involvement of the 5-HT1A receptor in mild serotonin toxicity without hyperthermia.
Correspondence: Masashi Nibuya Department of Psychiatry, National Defense Medical College, Namiki 3-2, Tokorozawa, Saitama 359-85I3, Japan Email nibrin@ndmc.ac.jp (c) (i) (-) 2014 Nakayama et al. This work is published by Dove Medical Press Limited, and licensed under Creative Commons Atribution - Non Commercial (unported, v3.0) $\mathrm{BY}$ NC License. The full terms of the License are available at http://creativecommons.org/licenses/by-n/3.0/. Non-commercial uses of the work are permitted without any further
permission from Dove Medical Press Limited, provided the work is properly attributed. Permissions beyond the scope of the License are administered by Dove Medical Press Limited. Information on permission from Dove Medical Press Limited, provided the work is properly attributed. Pe
how to request permission may be found at: http://www.dovepress.com/permissions.php 


\section{Case report}

\section{Case I}

A 64-year-old woman who experienced auditory hallucinations and insomnia, was treated with hypnotic benzodiazepines and perospirone $(8 \mathrm{mg} /$ day; Figure 1A). Perospirone had been administered for 4 months. She had developed chronic renal failure, which had continued for several years, with high serum levels of creatinine and blood urea nitrogen (Figure 1A). She also experienced depressed mood, diminished interest, and anhedonia; therefore, she was treated with paroxetine $(10 \mathrm{mg} /$ day $)$. Eighteen hours after paroxetine was added to her ongoing perospirone treatment, she exhibited finger tremors, sweating, coarse shivering, hyperactive knee jerks, vomiting, diarrhea, tachycardia, and psychomotor agitation. After administrating paroxetine with perospirone twice, both paroxetine and perospirone were discontinued. Her symptoms gradually disappeared over a period of approximately 1 week.

\section{Case 2}

An 81-year-old woman who experienced persecutory delusions with mild dementia, was treated with neuroleptics (Figure 1B). She was admitted to a psychiatric unit, owing to increased hostility and aggression related to her delusions. The results of brain imaging tests revealed mild brain atrophy in the frontotemporal and hippocampal regions with no cerebrovascular lesions. After successful treatment of her paranoid state, the patient developed depressive symptoms, which were treated with $10 \mathrm{mg} /$ day of paroxetine. The final

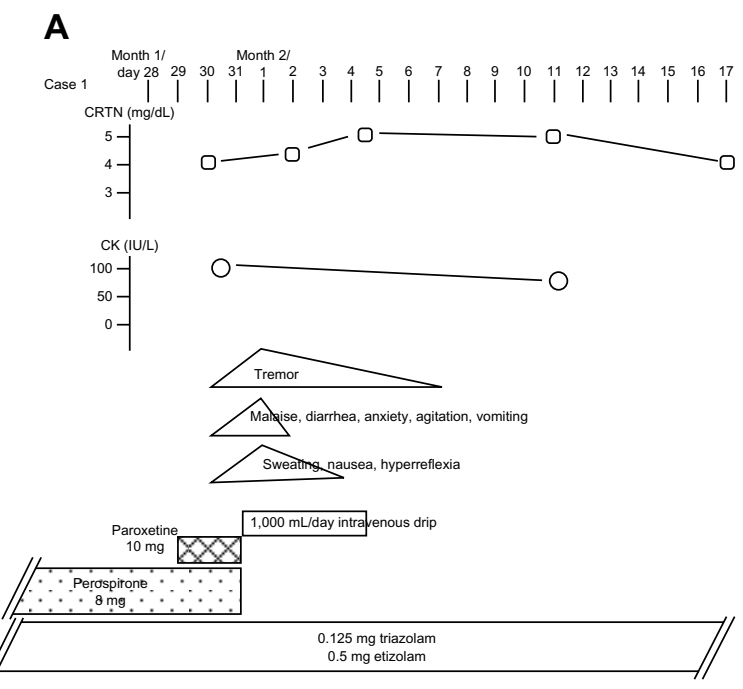

neuroleptic dose was $8 \mathrm{mg} /$ day of perospirone that had been administered for 3 weeks. Fourteen hours after the addition of paroxetine to the patient's ongoing perospirone treatment, she exhibited tachycardia, finger tremors, prominent anxiety and agitation, and hyperactive knee jerks. The symptoms continued for days (ie, for as long as perospirone and paroxetine were coadministered), and they disappeared 3 days after the discontinuation of both drugs.

\section{Discussion}

In the present report, both patients were diagnosed as having serotonin toxicity because of the existence of tremor and hyperreflexia, ${ }^{2}$ and they presented without symptoms of muscle rigidity or hyperthermia. ${ }^{1}$ The possibility of neuroleptic malignant syndrome was not taken into consideration as a differential diagnosis, because the symptoms appeared just after adding paroxetine; moreover, the present cases did not exhibit severe muscle rigidity and hyperthermia. ${ }^{3}$ In addition, there was no elevation of serum creatine phosphokinase in case 1 . The autonomic symptoms, neuromuscular hyperactivity, and altered mental status occurred upon initiation of the serotonergic drugs, and they ceased promptly after the treatment's discontinuation; this is characteristic of serotonin toxicity. ${ }^{4}$

Paroxetine is metabolized by cytochrome P450 oxidase (CYP)2D6 in the liver and excreted in the urine. Patients with renal failure are considered to be at an increased risk of developing side effects associated with a high serum concentration of paroxetine. ${ }^{5}$ The psychiatric diagnosis of

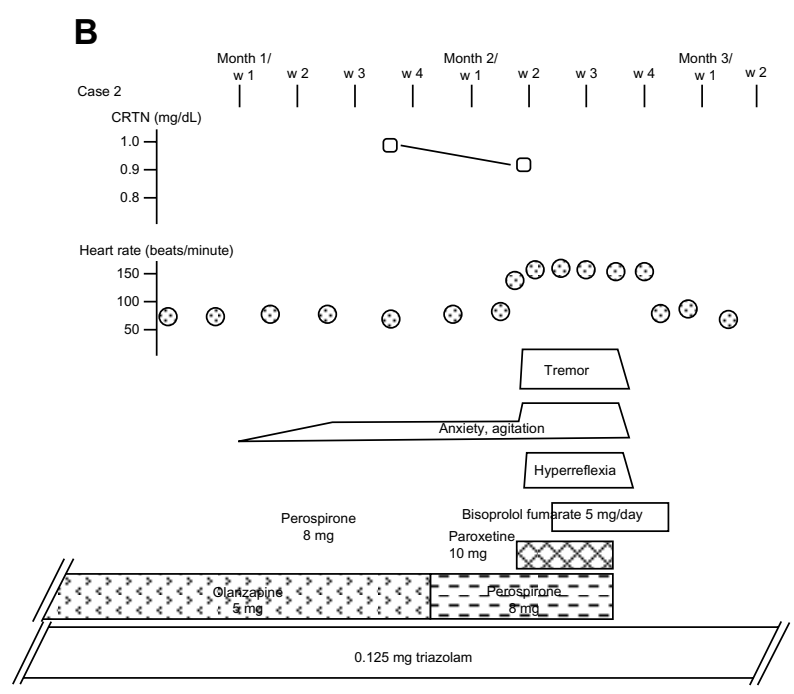

Figure I Measured concentrations of serum CRTN, CK, side effect symptoms, and administered drugs for cases I and 2.

Notes: (A) Case I: Measured concentrations of serum CRTN, CK (normal range of 0-160 IU/L), side effect symptoms, and administered drugs are shown. (B) Case 2: Concentrations of serum CRTN and accelerated heart rate, in addition to side effect symptoms and administered drugs, are shown. Bisoprolol fumarate, a $\beta$-adrenergic receptor antagonist metabolized by CYP2D6, was used to treat tachycardia, and neither a deterioration of depressive symptoms nor a worsening of serotonin toxicity was observed upon its administration.

Abbreviations: CRTN, creatinine; CK, creatine phosphokinase; w, week; CYP, cytochrome P450. 
Case 1 was psychotic disorder not otherwise specified, and there was no evidence of a relationship between her renal insufficiency and her psychiatric symptoms or her serotonin toxicity symptoms.

Case 2 was diagnosed as having dementia with psychotic symptoms, including persecutory delusions, anxiety, and depressive symptoms. In this case, the serotonin toxicity persisted for days because of the unfortunate oversight of a possible serotonin toxicity induced by the administered psychotropics. The increased anxiety and agitation were believed to be derived from the behavioral and psychological symptoms of dementia. Tachycardia was misdiagnosed as a result of the increased motor activity associated with her anxiety and agitation. Serum paroxetine concentrations were not evaluated in either case presented here, and the possibility remains that the paroxetine concentration was sufficiently elevated in both cases. We considered that vulnerability induced by perospirone pretreatment is most likely to have exaggerated the mild serotonin toxicity in both cases.

Perospirone is a serotonin-dopamine antagonist with unique agonistic effects on the 5-HT1A receptors, ${ }^{6}$ and is metabolized by CYP3A4. ${ }^{7}$ It was the second serotonindopamine antagonist after risperidone to be introduced to the Japanese neuroleptics market in 2001. The receptor binding profiles of perospirone (excluding 5-HT1A receptor binding) and its pharmacological properties targeting the positive and negative symptoms of schizophrenia resemble those of risperidone. ${ }^{7}$ The $\mathrm{K}_{\mathrm{i}}$ values of perospirone for the dopamine receptor D2, as well as for the 5-HT2A and 5-HT1A receptors are $1.4 \mathrm{nM}, 0.6 \mathrm{nM}$, and $2.9 \mathrm{nM}$, respectively, ${ }^{7}$ whereas those of risperidone are $3.3 \mathrm{nM}, 0.16 \mathrm{nM}$, and $250 \mathrm{nM}$, respectively. ${ }^{8}$ Data on the $\mathrm{K}_{\mathrm{i}}$ values measured from various tissue sources can be viewed in the National Institute of Mental Health Psychoactive Drug Screening Program K database (http://pdsp.med.unc.edu/pdsp.php) by choosing a psychotropic drug for the test ligand. The 5-HT1A agonist activity of neuroleptics is expected to improve $\operatorname{mood}^{9}$ and cognition ${ }^{10}$ in schizophrenia. Perospirone has also shown efficacy in reducing aggressive behavior in dementia patients. ${ }^{11}$ To treat the symptoms of aggression and anxiety exhibited by Case 2, previously administered olanzapine was switched to perospirone 10 days before the addition of paroxetine.

Two serotonergic receptor subtypes have been implicated in the etiology of serotonin toxicity. When experimental animals were administered a 5-HT1A agonist, they developed tremors, forepaw treading, head-weaving and twitches, flattened body posture, hind limb abduction, the Straub tail reaction, hyperhidrosis, and defecation. ${ }^{12}$ The similarities noted between the alterations in animal behavior and the symptoms of human serotonin toxicity suggest that the 5-HT1A receptor may be involved in the pathogenesis of serotonin toxicity. In another experimental animal model of serotonin toxicity, the activation of neuronal 5-HT2A receptors was identified as the cause of life-threatening hyperthermia. ${ }^{13}$ Furthermore, the serotonin system has been implicated in a biphasic mechanism that controls thermoregulation. Studies in experimental animals have indicated that a slight elevation of serotonin levels decreases body temperature through neural transmission involving the 5-HT1A receptors, whereas the considerable elevation of serotonin levels induces high body temperature through 5-HT2A neural transmission. ${ }^{14,15}$ Therefore, it could be hypothesized that while a slight excess of serotonin causes side effects by activating the 5-HT1A receptor, a significant increase in serotonin levels can induce lethal side effects with hyperthermia, which can cause severe brain damage ${ }^{16}$ through the activation of the 5-HT2A receptor. The early observation ${ }^{17}$ that the affinity of endogenous serotonin for the 5-HT1A receptors $\left(\mathrm{K}_{\mathrm{i}}=5.1 \mathrm{nM}\right)$ is much higher than its affinity for 5-HT2A receptors $\left(\mathrm{K}_{\mathrm{i}}=420 \mathrm{nM}\right)$ supports this hypothesis.

Vulnerabilities to serotonin toxicity are increased by a polymorphism in the serotonin transporter or CYP, a competitive substrate of the CYP enzyme, ${ }^{18}$ and by coadministered monoamine oxidase inhibitors or lithium. ${ }^{19}$ The present cases underscore the importance of preventing the development of serotonin toxicity after the combined use of SSRIs and 5-HT1A agonistic drugs, even when a small amount of SSRI is administered.

Several case studies have reported the development of serotonin toxicity by the combined use of SSRIs and 5-HT1A agonist anxiolytics; ${ }^{20,21}$ however, high body temperatures were not observed in these studies. The exacerbation of serotonin toxicity in the present cases by adding small doses of paroxetine while administering perospirone - acting both as a 5-HT1A receptor agonist and a 5-HT2A receptor antagonist - clearly indicates the involvement of the 5-HT1A receptor in mild forms of serotonin toxicity. Although the involvement of both 5-HT1A and 5-HT2A receptors in the pathogenesis of serotonin toxicity has often been indicated, ${ }^{22}$ we considered it worthwhile to pay attention to serotonin toxicity profiles under the situation of an antagonistic blockade of 5-HT2A receptors in human subjects.

Taken together, the coadministration of SSRIs and neuroleptics, like risperidone, with a potent 5-HT2A antagonistic function and a scarce 5-HT1A agonistic function would produce a lower incidence of serotonin toxicity. 
The coadministration of SSRIs with psychotropics possessing 5-HT1 A agonist properties has received increasing attention. A recent clinical trial ${ }^{23}$ indicated the effectiveness of adding a 5-HT1A partial agonist for the treatment of patients with depression who are resistant to citalopram. Mirtazapine, which acts as a 5-HT1A agonist in addition to its norepinephrinereleasing function, has been proposed to enhance the clinical effectiveness of SSRIs. ${ }^{24}$ Furthermore, aripiprazole, which acts as a 5-HT1A agonist, is used to augment the clinical effectiveness of SSRI treatment. ${ }^{25}$ Considering that recently available SSRIs, including vilazodone ${ }^{26}$ and vortioxetine, ${ }^{27}$ have considerable 5-HT1A agonistic function, more caution is needed to detect serotonin toxicity in depression treatments.

In conclusion, the possible development of serotonin toxicity should be considered when neuromuscular toxicities including tremor, myoclonus, and hyperreflexia in the extremities are observed during the combined use of SSRIs and psychotropics with 5-HT1A agonistic properties, or during the use of SSRIs with 5-HT1A agonistic properties.

\section{Acknowledgments}

The authors would like to thank Dr Akira Monji at Saga University (Saga, Japan) for his suggestions.

\section{Disclosure}

The authors report no conflicts of interest in this work.

\section{References}

1. Boyer EW, Shannon M. The serotonin syndrome. $N$ Engl J Med. 2005;352(11):1112-1120.

2. Dunkley EJ, Isbister GK, Sibbritt D, Dawson AH, Whyte IM. The Hunter Serotonin Toxicity Criteria: simple and accurate diagnostic decision rules for serotonin toxicity. QJM. 2003;96(9):635-642.

3. American Psychiatric Association. Diagnostic and Statistical Manual of Mental Disorders, Fourth Edition, Text Revision (DSM-IV TR). Washington DC: American Psychiatric Association; 2000:795-798.

4. Isbister GK, Buckley NA, Whyte IM. Serotonin toxicity: a practical approach to diagnosis and treatment. Med J Aust. 2007;187(6): 361-365.

5. Herr KD, Nemeroff CB. Paroxetine. In: Schatzberg AF, Nemeroff CB, editors. The American Psychiatric Publishing Textbook of Psychopharmacology. 3rd ed. Arlington, VA: American Psychiatric Publishing; 2004:259-281.

6. Odagaki Y, Toyoshima R. 5-HT1A receptor agonist properties of antipsychotics determined by [35S]GTPgammaS binding in rat hippocampal membranes. Clin Exp Pharmacol Physiol. 2007;34(5-6): 462-466.

7. Ishibashi T, Ohno Y. Perospirone hydrochloride: the novel atypical antipsychotic agent with high affinities for 5-HT2, D2 and 5-HT1A receptors. Biogenic Amines. 2004;18:307-311.
8. Schotte A, Janssen PF, Gommeren W, et al. Risperidone compared with new and reference antipsychotic drugs: in vitro and in vivo receptor binding. Psychopharmacology (Berl). 1996;124(1-2):57-73.

9. Newman-Tancredi A. The importance of 5-HT1A receptor agonism in antipsychotic drug action: rationale and perspectives. Curr Opin Investig Drugs. 2010;11(7):802-812.

10. Meltzer HY, Sumiyoshi T. Does stimulation of 5-HT(1A) receptors improve cognition in schizophrenia? Behav Brain Res. 2008;195(1): 98-102.

11. Sato S, Mizukami K, Moro K, Tanaka Y, Asada T. Efficacy of perospirone in the management of aggressive behavior associated with dementia. Prog Neuropsychopharmacol Biol Psychiatry. 2006;30(4):679-683.

12. Smith LM, Peroutka SJ. Differential effects of 5-hydroxytryptamine1a selective drugs on the 5-HT behavioral syndrome. Pharmacol Biochem Behav. 1986;24(6):1513-1519.

13. Nisijima K, Shioda K, Iwamura T. Neuroleptic malignant syndrome and serotonin syndrome. Prog Brain Res. 2007;162:81-104.

14. Abdel-Fattah AF, Matsumoto K, el-Hady KA, Watanabe H. 5-HT1A and 5-HT2 receptors mediate hypo- and hyperthermic effects of tryptophan in pargyline-pretreated rats. Pharmacol Biochem Behav. 1995;52(2):379-384.

15. Nisijima K, Yoshino T, Yui K, Katoh S. Potent serotonin (5-HT) (2A) receptor antagonists completely prevent the development of hyperthermia in an animal model of the 5-HT syndrome. Brain Res. 2001;890(1):23-31.

16. Slettedal JK, Nilssen DO, Magelssen M, Løberg EM, Maehlen J. Brain pathology in fatal serotonin syndrome: presentation of two cases. Neuropathology. 2011;31(3):265-270.

17. Dalpiaz A, Gessi S, Borea PA, Gilli G. Binding thermodynamics of serotonin to rat-brain 5-HT1A, 5HT2A and 5-HT3 receptors. Life Sci. 1995;57(12):PL141-PL146.

18. Tanaka A, Nagamatsu T, Yamaguchi M, et al. Myoclonus after dextromethorphan administration in peritoneal dialysis. Ann Pharmacother. 2011;45(1):e1.

19. Kalueff AV, LaPorte JL, Murphy DL. Perspectives on genetic animal models of serotonin toxicity. Neurochem Int. 2008;52(4-5):649-658.

20. Lauterbach EC. Fluoxetine, buspirone, myoclonus, and dystonia. Am J Psychiatry. 1995;152(11):1697.

21. Manos GH. Possible serotonin syndrome associated with buspirone added to fluoxetine. Ann Pharmacother. 2000;34(7-8):871-874.

22. Odagaki Y. Atypical neuroleptic malignant syndrome or serotonin toxicity associated with atypical antipsychotics? Curr Drug Saf. 2009;4(1):84-93.

23. Trivedi MH, Fava M, Wisniewski SR, et al; STAR*D Study Team. Medication augmentation after the failure of SSRIs for depression. N Engl J Med. 2006;354(12):1243-1252.

24. Carpenter LL, Yasmin S, Price LH. A double-blind, placebo-controlled study of antidepressant augmentation with mirtazapine. Biol Psychiatry. 2002;51(2):183-188.

25. Worthington JJ 3rd, Kinrys G, Wygant LE, Pollack MH. Aripiprazole as an augmentor of selective serotonin reuptake inhibitors in depression and anxiety disorder patients. Int Clin Psychopharmacol. 2005;20(1):9-11.

26. Heinrich T, Böttcher H, Gericke R, et al. Synthesis and structure - activity relationship in a class of indolebutylpiperazines as dual 5-HT(1A) receptor agonists and serotonin reuptake inhibitors. $J$ Med Chem. 2004;47(19):4684-4692.

27. Bang-Andersen B, Ruhland T, Jørgensen M, et al. Discovery of 1-[2-(2,4-dimethylphenylsulfanyl)phenyl]piperazine (Lu AA21004): a novel multimodal compound for the treatment of major depressive disorder. J Med Chem. 2011;54(9):3206-3221. 
Neuropsychiatric Disease and Treatment

Dovepress

\section{Publish your work in this journal}

Neuropsychiatric Disease and Treatment is an international, peerreviewed journal of clinical therapeutics and pharmacology focusing on concise rapid reporting of clinical or pre-clinical studies on a range of neuropsychiatric and neurological disorders. This journa is indexed on PubMed Central, the 'PsycINFO' database and CAS.

The manuscript management system is completely online and includes a very quick and fair peer-review system, which is all easy to use. Visit http://www.dovepress.com/testimonials.php to read real quotes from published authors.

Submit your manuscript here: http://www.dovepress.com/neuropsychiatric-disease-and-treatment-journal 